\title{
Use of discard pleural fluid in molecular research
}

\section{Frederic W. Grannis Jr}

The October 2011 issue of Nature Reviews Clinical Oncology included a Perspectives article by Olson et al. (The ethical use of mandatory research biopsies. Nat. Rev. Clin. Oncol. 8, 620-625) ${ }^{1}$ on the ethical dilemma faced by researchers and institutional review boards (IRBs) when a molecular research study requires obtaining multiple tissue samples from the internal organs of patients with solid tumors during the course of treatment. Although such biopsy material is of potential use for the analysis of molecular changes in tumor cells following treatment, IRBs are reluctant to allow the inclusion of serial biopsies in human research protocols, as serial biopsies of solid tumors provide no direct benefit to the patient and might cause anxiety, discomfort, bleeding or other serious complications (F. Grannis, personal communication). However, there is a simple, safe, ethical and inexpensive alternative that can resolve the clinical and ethical objections to obtaining serial samples of cancer cells during treatment.

Malignant pleural effusions are found in as many as 100,000 patients with cancermost commonly in those with lung and breast cancers-every year in the US. ${ }^{2}$ To provide relief from shortness of breath caused by pleural effusions, patients are treated by the placement of tunneled pleural catheters. ${ }^{3,4}$ Following the placement of a catheter, the patient's caregivers drain the pleural effusions at frequent intervals in outpatient settings and discard the pleural fluid. The discarded fluid is of potential use in molecular research as malignant plural effusions are known to be cytologically positive for cancer cells in about $50 \%$ of patients. ${ }^{5,6}$ On several occasions, cancer cell lines have been developed from these effusions. ${ }^{7,8}$ The opportunity to serially harvest cells from the discarded fluid during the course of treatment offers the possibility of analyzing the molecular changes in patients' cancer cells.

About $40 \%$ of patients with lung cancer develop pleural effusions during the disease trajectory. ${ }^{9,10}$ Thus, it should be possible to perform a baseline molecular analysis of cancer cells in the effusion before the start of treatment, and repeat analyses can be performed after treatment, which will allow the characterization of molecular changes. The discarded fluid could also be used to study the pharmacokinetics of the experimental drugs, or drugs might be delivered directly into the pleural cavity. Furthermore, the IRBs and regulatory agencies should have no clinical or ethical concerns over the use of the currently discarded fluid for research purposes, as the fluid can be obtained via standard palliative interventions that are used to provide relief and, as our experience shows, are not associated with a risk of complications and do not cause discomfort or cost to the patients.

All patients with malignant pleural effusions can be treated with pleural catheters. In most cases, the decision about whether to use talc pleurodesis is based on the patient's convenience, as both methods have approximately the same success rate. ${ }^{11}$

City of Hope National Medical Center, 1500 East Duarte Road, Duarte, CA 91010, USA. fgrannis@coh.org
Competing interests

The author declares an association with the following company: CareFusion. See the article online for full details of the relationship.

1. Olson, E. M., Lin, N. U., Krop, I. E. \& Winer, E. P. The ethical use of mandatory research biopsies. Nat. Rev. Clin. Oncol. 8, 620-625 (2011).

2. Grannis, F. W. Jr \& Lai, L. in Cancer Management: a Multidisciplinary Approach $13^{\text {th }}$ edn Ch. 40 (eds. Pazdur, R., Wagman, L. D. Camphausen, K. A. \& Hoskins, W. J.) (UBM Medica, Connecticut, 2010).

3. Pleur $\mathrm{X}^{\circledR}$ Catheter System. CareFusion Corporation [online], http://www.carefusion. com/medical-products/interventionalprocedures/drainage/pleurx/index.aspx (2011).

4. Aspira Pleural Drainage System. Bard Access Systems [online], http://www.bardaccess.com/ drainage-aspira.php (2011).

5. Fiegl, M. et al. Sensitive detection of tumour cells in effusions by combining cytology and fluorescence in situ hybridisation (FISH). Br. J. Cancer 91, 558-563 (2004).

6. Davidson, B. et al. Detection of cancer cells in effusions from patients diagnosed with gynaecological malignancies. Evaluation of five epithelial markers. Virchows Arch. 435, 43-49 (1999).

7. Schmidt, M. et al. A novel breast cancer cell line initially established from pleural effusion: evolution towards a more aggressive phenotype. Int. J. Oncol. 30, 565-572 (2007).

8. Watanabe, M. et al. Establishment of the human BSMZ breast cancer cell line, which overexpresses the erbB-2 and c-myc genes. Cancer Res. 52, 5178-5182 (1992).

9. Sugiura, S. et al. Prognostic value of pleural effusion in patients with non-small cell lung cancer. Clin. Cancer Res. 3, 47-50 (1997).

10. Cullinane, C. A., Paz, I. B., Smith, D., Carter, N. $\&$ Grannis, F. W. Jr. Prognostic factors in the surgical management of pericardial effusion in the patient with concurrent malignancy. Chest 125, 1328-1334 (2004).

11. Olden, A. M. \& Holloway, R. Treatment of malignant pleural effusion: PleuRx catheter or talc pleurodesis? A cost-effectiveness analysis. J. Palliat. Med. 13, 59-65 (2010). 